\title{
Danish Gynecological Cancer Database
}

This article was published in the following Dove Press journal:

Clinical Epidemiology

25 October 2016

Number of times this article has been viewed

\section{Sarah Mejer Sørensen'}

Signe Frahm Bjørn'

Kirsten Marie Jochumsen ${ }^{2}$

Pernille Tine Jensen ${ }^{2}$

Ingrid Regitze Thranov'

Helle Hare-Bruun ${ }^{3}$

Lene Seibæk ${ }^{4}$

Claus Høgdall'

'Department of Gynecology, Rigshospitalet, University of Copenhagen, Copenhagen, Denmark;

${ }^{2}$ Department of Obstetrics and Gynecology, Odense University

Hospital, Odense, Denmark; ${ }^{3}$ Research

Centre for Prevention and Health, The

Capital Region of Denmark, Glostrup,

Denmark; ${ }^{4}$ Department of Gynecology

and Obstetrics, Aarhus University

Hospital, Aarhus, Denmark
Correspondence: Sarah Mejer Sørensen Department of Gynecology,

Rigshospitalet, University of Copenhagen, Blegdamsvej 9, 2100 Copenhagen,

Denmark

Tel +4522979956

Fax +4535454285

Email sarah.mejer.soerensen@regionh.dk
Aim of database: The Danish Gynecological Cancer Database (DGCD) is a nationwide clinical cancer database and its aim is to monitor the treatment quality of Danish gynecological cancer patients, and to generate data for scientific purposes. DGCD also records detailed data on the diagnostic measures for gynecological cancer.

Study population: DGCD was initiated January 1, 2005, and includes all patients treated at Danish hospitals for cancer of the ovaries, peritoneum, fallopian tubes, cervix, vulva, vagina, and uterus, including rare histological types.

Main variables: DGCD data are organized within separate data forms as follows: clinical data, surgery, pathology, pre- and postoperative care, complications, follow-up visits, and final quality check. DGCD is linked with additional data from the Danish "Pathology Registry", the "National Patient Registry", and the "Cause of Death Registry" using the unique Danish personal identification number (CPR number).

Descriptive data: Data from DGCD and registers are available online in the Statistical Analysis Software portal. The DGCD forms cover almost all possible clinical variables used to describe gynecological cancer courses. The only limitation is the registration of oncological treatment data, which is incomplete for a large number of patients.

Conclusion: The very complete collection of available data from more registries form one of the unique strengths of DGCD compared to many other clinical databases, and provides unique possibilities for validation and completeness of data. The success of the DGCD is illustrated through annual reports, high coverage, and several peer-reviewed DGCD-based publications.

Keywords: quality, research, gynecological cancer, operation, pathology, follow-up

\section{Aim of database}

The aim of the Danish Gynecological Cancer Database (DGCD) is to achieve the greatest possible knowledge regarding examination, treatment methods, and results within the field of gynecological cancer in Denmark. The purpose is treatment quality assurance and improvement, and generation of scientific data. ${ }^{1}$

\section{Study population}

DGCD is by definition nationwide: "a clinical quality registry where a minimum of $90 \%$ of the relevant patient population in Denmark is registered". ${ }^{2}$ The database was initiated on January 1, 2005. The database before June 1, 2013, is referred to as the old DGCD and the database after this date as the new DGCD. Data from the old DGCD are mapped into the new DGCD in order to assure continuity. Since July 2015, 19,729 patients had been registered in DGCD, on average 1,879 patients per year since January 1, 2005. submit your manuscript | www.dovepress.com

Dovepress

http://dx.doi.org/10.2147/CLEP.S99479 
Table I The DGCD's present patient population according to diagnosis

\begin{tabular}{|c|c|c|c|c|c|c|c|c|c|c|c|c|}
\hline & \multicolumn{2}{|c|}{$2014 / 2015$} & \multicolumn{2}{|c|}{$2013 / 2014$} & \multicolumn{2}{|c|}{$2012 / 2013$} & \multicolumn{2}{|c|}{$2011 / 2012^{a}$} & \multicolumn{2}{|c|}{$2005-20 I^{a}$} & \multicolumn{2}{|l|}{ Total } \\
\hline & $\mathbf{n}$ & $\%$ & $\mathbf{n}$ & $\%$ & $\mathbf{n}$ & $\%$ & $\mathbf{n}$ & $\%$ & $\mathbf{n}$ & $\%$ & $\mathbf{N}$ & $\%$ \\
\hline Ovarian cancer & 324 & 16.6 & 346 & 16.3 & 420 & 28.6 & 495 & 27.2 & 3,067 & 24.9 & 4,652 & 23.6 \\
\hline Tubal cancer & 27 & 1.4 & 40 & 1.9 & 28 & 1.9 & 23 & 1.3 & 197 & 1.6 & 315 & 1.6 \\
\hline Peritoneal cancer & 45 & 2.3 & 40 & 1.9 & 6 & 0.4 & I & 0.1 & 313 & 2.5 & 405 & 2.1 \\
\hline Borderline tumors & 124 & 6.3 & 159 & 7.5 & 119 & 8.1 & 133 & 7.3 & $\mathrm{I}, \mathrm{I} \mid 4$ & 9 & 1,649 & 8.4 \\
\hline Cancer of the cervix & 337 & 17.3 & 367 & 17.3 & 246 & 16.8 & 347 & 19.0 & 2,467 & 20 & 3,764 & 19.1 \\
\hline Vulvar cancer & 128 & 6.6 & 114 & 5.4 & 56 & 3.8 & 46 & 2.5 & - & - & 344 & 1.7 \\
\hline Vaginal cancer & 21 & I.I & 14 & 0.7 & - & - & I & 0.1 & - & - & 36 & 0.2 \\
\hline Trophoblast disease & 28 & 1.4 & 48 & 2. & 5 & 0.3 & I & 0.1 & - & - & 82 & 0.4 \\
\hline $\begin{array}{l}\text { Unknown ovarian or } \\
\text { peritoneal cancer }\end{array}$ & 94 & 4.8 & 99 & 4.7 & 7 & 0.5 & - & - & - & - & 200 & 1.0 \\
\hline Endometrial cancer & 718 & 36.8 & 788 & 37.1 & 566 & 38.6 & 775 & 42.5 & 4,718 & 38.2 & 7,565 & 38.4 \\
\hline $\begin{array}{l}\text { Uterine hyperplasia } \\
\text { with atypia }\end{array}$ & 107 & 5.5 & 109 & 5.1 & 13 & 0.9 & I & 0.1 & 463 & 3.8 & 693 & 3.5 \\
\hline Total & 1,953 & 100 & 2,124 & 100 & 1,466 & 100 & 1,823 & 100 & 12,339 & 100 & 19,705 & 100 \\
\hline
\end{tabular}

Note: a Due to the mapping of data from the old DGCD to the new DGCD, the number of patients enrolled in 2005-20II and the number of patients enrolled in $201 \mathrm{I} / 2012$ will have a small overlap.

Abbreviation: DGCD, Danish Gynecological Cancer Database.

Table 1 shows an overview of the patients currently enrolled in DGCD and the diagnoses that DGCD covers. ${ }^{3,4}$ As seen in Table 2, DGCD has had a high coverage rate throughout the years. The coverage estimates are based on the registrations in the Danish National Patient Registry (NPR).

\section{Main variables}

Data are registered online in special data forms programmed in the TietoEnator's quality measurement system. ${ }^{5}$ Data are placed on a central server hosted by the Registry Support Center (East) - Center for Clinical Quality Improvement and Health Informatics.

The data of DGCD are primarily recorded in four main online forms: clinical data, surgery, pathology, and final quality check. In the old DGCD, some of the variables were optional, thus resulting in varying registration of the optional variables. In the new DGCD, optional data requirements have been eliminated. Due to the setup of the old DGCD, it was possible to add and fill in data forms in a way in which the sequence of

Table 2 Data coverage during the life span of the database based on data from the database Quality Management System (QMS) and the Danish National Patient Registry (NPR)

\begin{tabular}{lllll}
\hline $\begin{array}{l}\text { DGCD national } \\
\text { report period }\end{array}$ & $\begin{array}{l}\text { Registered } \\
\text { in both QMS } \\
\text { and NPR, n }\end{array}$ & $\begin{array}{l}\text { Only in } \\
\text { QMS }\end{array}$ & $\begin{array}{l}\text { Only in } \\
\text { NPR }\end{array}$ & $\begin{array}{l}\text { Coverage } \\
\text { rate (\%) }\end{array}$ \\
\hline $2014 / 2015$ & 2,029 & 132 & 72 & 97 \\
$2013 / 2014$ & 2,239 & 85 & 43 & 98 \\
$2012 / 2013^{\text {a }}$ & 1,715 & 113 & 231 & 89 \\
$2005-2012$ & 14,869 & N/A & 480 & 97 \\
\hline
\end{tabular}

Notes: ${ }^{a}$ Due to increased scrutiny of the new database, there are fewer patients in the database from this period than previously reported. N/A: Data not available. Abbreviation: DGCD, Danish Gynecological Cancer Database. patient events were incorrectly registered. In order to get valid data, constant data review and time consuming correction by doctors and secretaries was needed. The structure of the data forms in the new DGCD ensures correct registration.

The first data form covers clinical data. The data are registered by gynecologists specializing in gynecological oncology. The second data form covers surgical data recorded by surgeons specializing in gynecological oncology. The third data form covers pathology data that are registered by a pathologist. All data forms are designed to logically and consecutively provide variables specific for each type of gynecological cancer and surgery.

Staging follows the "International Federation of Gynecology and Obstetrics" (FIGO) system. Staging reports are available both in the FIGO and Tumor Nodes Metastasis system. In case of ovarian cancer, the final staging is based on both surgical and pathological staging. In uterine cancers, the pathological staging is determinative. When the diagnosis is based only on a biopsy, the gynecological clinician can choose to stage the disease based on imaging and clinical findings. The staging follows the FIGO guidelines. Staging and treatment of cervical, vulva, and ovarian cancer is centralized in Denmark and only allowed in centers with specialized gynecological oncologists.

The fourth data form is the final quality check, which is recorded by the gynecologists. Data from all data forms described earlier are consolidated and from this the final staging and diagnosis is performed.

In the new DGCD, data forms for registering pre- and postoperative nurses' care and data forms for vulva/vaginal cancer and trophoblastic disease were added in 2013. 
Table 3 Main variables in DGCD - an overview

\begin{tabular}{|c|c|c|c|}
\hline Clinical data & Surgical data & Pathology & $\begin{array}{l}\text { Pre- and } \\
\text { postoperative } \\
\text { care }\end{array}$ \\
\hline Gynecological history & $\begin{array}{l}\text { Description of } \\
\text { Cancer spread, tumor size }\end{array}$ & $\begin{array}{l}\text { Macro- and microscopically } \\
\text { verified spread of the cancer }\end{array}$ & Psychosocial status \\
\hline Predispositions & Peritoneal carcinomatosis & $\begin{array}{l}\text { Cytology of peritoneal and } \\
\text { pleural fluids }\end{array}$ & Nutritional status \\
\hline Comorbidity & Metastases & Histology & Mobilization \\
\hline Smoking and alcohol & Ascites & Histological type & Vital functions \\
\hline BMI & Performed surgery & WHO grade & Pain score \\
\hline $\begin{array}{l}\text { Risk of malignancy } \\
\text { index (RMI) }\end{array}$ & Extent of surgery & FIGO stage & \\
\hline $\begin{array}{l}\text { Data on preoperative } \\
\text { physical findings }\end{array}$ & Resection of other organs & & \\
\hline Choice of treatment & $\begin{array}{l}\text { Operative time } \\
\text { Surgical outcome } \\
\text { Residual tumor size } \\
\text { Residual carcinomatosis } \\
\text { Incidental lesions to other organs } \\
\text { Operative surgical stage } \\
\text { Blood loss } \\
\text { Surgical complications (within } \\
30 \text { days postoperative) }\end{array}$ & & \\
\hline
\end{tabular}

Abbreviations: DGCD, Danish Gynecological Cancer Database; BMI, body mass index; WHO, World Health Organization; FIGO, International Federation of Gynecology and Obstetrics.

An overview of the main variables in DGCD is presented in Table 3. The old DGCD also included a data form for registration of data regarding the oncological treatment.

Due to poor cover rate, this data form was omitted in the new DGCD. Oncologic data in the new DGCD are imported from the NPR which only includes date and type of oncologic treatment.

In addition, data such as diagnosis, duration of hospitalization, and perioperative complications are drawn from the NPR. In this way, DGCD data are both validated and supplemented. Pathological data regarding histology and relapse biopsies are drawn from the Danish Pathology Register, data regarding cause of death from the Cause of Death Register, and overall survival from the Civil Registration System, which is updated day-to-day.

\section{Follow-up}

Data regarding follow-up are registered in DGCD with a form describing each follow-up visit, including registration of relapse and residual disease. The unique nationwide Civil Registration System and Cause of Death Register ensure virtually complete follow-up of all patients recorded in the DGCD. Until recently, Danish gynecologic cancer patients had follow-up visits at the hospital for 5 years or to recurrence and/or death. According to new guidelines from the National Institute of Health, follow-up visits after the first year will now be based on need.

\section{Examples of research}

DGCD has formed the basis of several scientific studies and publications. This spans from scholarship fellows and bachelor theses to $\mathrm{PhD}$ theses, doctoral theses, and post-doc publications. In 2014 alone, DGCD data were used in nine ongoing $\mathrm{PhD}$ projects and three ongoing post-docs. ${ }^{6}$

Several DGCD studies have been published for assurance of quality. Fagö-Olsen et al demonstrated in 2011 that centralization of treatment for ovarian cancer improves survival. It was shown that patients with stage IIIC and IV ovarian cancer benefit from treatment in a tertiary referral center. ${ }^{7}$

Another quality study based solely on DGCD data by Håkansson et al in 2012 validated the use of the risk of malignancy index (RMI) as a tool for ovarian cancer risk assessment and referral to a tertiary center. They found that RMI $\geq 200$ was a reliable tool for identifying patients with ovarian cancer. ${ }^{8}$

In 2014, Svolgaard et al published an article for assurance of quality based on DGCD data. The aim was to evaluate the Danish nationwide progress in implementing lymphadenectomy for women presenting with tumor(s) macroscopically confined to the ovary, and the effect of lymphadenectomy on the overall survival. The study concluded that the national number of lymphadenectomies was too low, although increasing, and that the effect of lymphadenectomies on overall survival was not significant. ${ }^{9}$ The results of the study formed the basis for a very intense debate about systematic lymph- 
adenectomy and revision of guidelines. DGCD publishes annual reports, which are widely used as a source of quality results of Danish gynecologic cancer treatment. ${ }^{3}$

A DGCD validation study from 2014 concluded: the data on endometrial cancer registered in the DGCD regarding surgery and pathology is valid and complete, and they provide a solid base for research. ${ }^{10}$ The completeness of data on pathology and surgery reported to the DGCD was $97.3 \%$ and the agreement for the reported data in the DGCD was $88.3 \% .^{10}$

A DGCD validation study on postoperative complications in ovarian cancer, tubal cancer, and ovarian borderline tumor patients showed that the completeness of reporting to the DGCD was $94.2 \%$ and the strength of agreement between the variables in the DGCD and the medical file varied from moderate to very good. ${ }^{11}$ A new large validation study on ovarian cancer based on a combination of NPR and DGCD variables is currently under progress (personal communication by Sørensen et al, March 6, 2016). DGCD has also been used in studies showing how comorbidity independently affects overall survival in women with uterine or ovarian cancer. ${ }^{12}$

DGCD is furthermore extensively used in translational and clinical national and international studies as data are easily combined with data from the Danish Cancer Biobank. ${ }^{13-16}$ In one of the first DGCD-based translational studies from 2010 performed by Petri et al, data from DGCD combined with material from the Danish Cancer Biobank were used in comparison of proteomic biomarker panels in urine and serum for ovarian cancer diagnosis. The authors concluded that urine and serum proteomic panels can be used individually or in combination in ovarian cancer diagnostics. ${ }^{17}$

The Danish Multidisciplinary Cancer Group (DMCG) produced a report on cancer survival in Denmark in the period 1995-2012. ${ }^{18}$ This report included calculations of ovarian cancer survival based on DGCD data. The report showed that the 5 -year survival for ovarian cancer was $37 \%$ in the period 2005-2009, that the mortality rates of ovarian cancer patients in Denmark have been decreasing since 1995, and the survival trends have been gradually increasing since 2000. This report provided important information on trends in the management and prognosis of ovarian cancer. Edwards et al have continued working on the report. ${ }^{19}$

\section{Administrative issues and funding}

The DGCD is funded by the Danish regions. The monitoring and improvement of the treatment quality of gynecological cancer is the key objective that ensures the funding of DGCD, which is anchored to the national expert group, the Danish Gynecological Cancer Group, consisting of clinicians and researchers responsible for developing and maintaining national clinical guidelines for the treatment of gynecological cancer. DGCD is under the auspices of the DMCG; an umbrella organization comprised of 24 national, diseasespecific cancer groups and clinical databases. The running and maintenance of DGCD is managed by the DGCD steering committee, which consists of a chairperson and 14 members appointed by the Danish Gynecological Cancer Group board and the Registry Support Centre (East) - Centre for Clinical Quality Improvement and Health Informatics.

Table 4 Clinical quality indicators used

\begin{tabular}{|c|c|c|}
\hline $\begin{array}{l}\text { Indicator } \\
\text { area }\end{array}$ & Indicator name & Standard \\
\hline \multirow[t]{3}{*}{$\begin{array}{l}\text { Cervical } \\
\text { cancer }\end{array}$} & $\begin{array}{l}\text { Cervical cancer, percentage of patients } \\
\text { with removal of } \geq 18 \text { lymph nodes during } \\
\text { radical hysterectomy }\end{array}$ & $\geq 80 \%$ \\
\hline & $\begin{array}{l}\text { Cervical cancer, 5-year survival FIGO } \\
\text { stage I }\end{array}$ & $\geq 90 \%$ \\
\hline & $\begin{array}{l}\text { Cervical cancer, 5-year survival FIGO } \\
\text { stage II-III }\end{array}$ & $\geq 45 \%$ \\
\hline \multirow[t]{6}{*}{$\begin{array}{l}\text { Ovarian } \\
\text { cancer }\end{array}$} & $\begin{array}{l}\text { Ovarian cancer, primary radical surgery, } \\
\text { FIGO stage IIIC-IV, surgery }\end{array}$ & $\geq 60 \%$ \\
\hline & $\begin{array}{l}\text { Ovarian cancer, radical surgery after } \\
\text { neoadjuvant chemotherapy, FIGO } \\
\text { stage IIIC-IV }\end{array}$ & $\geq 60 \%$ \\
\hline & $\begin{array}{l}\text { Ovarian cancer, performed radical } \\
\text { lymphadenectomy, FIGO stage I-IIIA }\end{array}$ & $\geq 80 \%$ \\
\hline & $\begin{array}{l}\text { Ovarian cancer, performed radical } \\
\text { lymphadenectomy, FIGO stage IIIB-IV }\end{array}$ & $\geq 80 \%$ \\
\hline & $\begin{array}{l}\text { Ovarian cancer, postoperative hospitalization } \\
\leq 8 \text { days after primary surgery }\end{array}$ & $\geq 80 \%$ \\
\hline & $\begin{array}{l}\text { Ovarian cancer, postoperative hospitalization } \\
\leq 8 \text { days after surgery performed after } \\
\text { neoadjuvant chemotherapy }\end{array}$ & $\geq 80 \%$ \\
\hline \multirow[t]{2}{*}{$\begin{array}{l}\text { Endometrial } \\
\text { cancer }\end{array}$} & $\begin{array}{l}\text { Endometrial cancer, no lymphadenectomy, } \\
\text { for low risk patients FIGO stage I }\end{array}$ & $\geq 85 \%$ \\
\hline & $\begin{array}{l}\text { Endometrial cancer, removal of pelvic } \\
\text { lymph nodes for mid-high risk patients } \\
\text { FIGO stage I or II-III }\end{array}$ & $\geq 80 \%$ \\
\hline \multirow[t]{2}{*}{$\begin{array}{l}\text { Nurses' } \\
\text { treatment }\end{array}$} & $\begin{array}{l}\text { Nurses, ovarian cancer - mobilization } \\
\text { of non-extensively operated patients } \\
\geq 3 \text { hours on postoperative day I }\end{array}$ & $\geq 60 \%$ \\
\hline & $\begin{array}{l}\text { Nurses, ovarian cancer }- \text { number of } \\
\text { patients with defecation } \leq 3 \text { days } \\
\text { postoperative }\end{array}$ & $\geq 80 \%$ \\
\hline \multicolumn{3}{|c|}{ Suggestions of new indicators } \\
\hline Vulvar cancer & $\begin{array}{l}\text { Vulvar cancer, sentinel node biopsy } \\
\text { performed on patients with FIGO } \\
\text { stage IB, tumor size } \leq 4 \mathrm{~cm} \text { and no palpable } \\
\text { inguinal nodes }\end{array}$ & $\geq 70 \%$ \\
\hline $\begin{array}{l}\text { Trophoblastic } \\
\text { disease }\end{array}$ & $\begin{array}{l}\text { Trophoblastic disease (only molar); } \\
\text { genetic analysis performed }\end{array}$ & $\geq 75 \%$ \\
\hline
\end{tabular}

Abbreviation: FIGO, International Federation of Gynecology and Obstetrics. 
To ensure maximal coverage rate, shortage lists are created specifically for each hospital and continually updated. The steering committee develops the annual DGCD report and clinical quality indicators in cooperation with Registry Support Centre (East) - Epidemiology and Biostatistics. The present 13 quality indicators, which are used to monitor the quality of the management of gynecological cancer between different regions of Denmark and across hospitals, are presented in Table 4 . The quality indicators are under constant validation and development. ${ }^{3}$

\section{Conclusion}

The DGCD is a large compulsory nationwide clinical database with a high coverage of all gynecological cancers. The large number of variables provides a basis for several quality and research publications. The selected data from all the registers are, together with DGCD data, available in a structured form in the Statistical Analysis Software portal and as raw data. This very complete collection of available data from several registers forms one of the unique strengths of DGCD, compared to many other clinical databases. It provides unique possibilities for validation and completeness of data. Other unique strengths of the DGCD are the high coverage, almost $100 \%$ follow-up, and that DGCD represents data from all Danish patients with a gynecologic malignancy with minimal risk of selection bias in research and presentations. One of the major problems in DGCD registration is the lack of specific oncology data such as more detailed oncologic treatment, oncologic complications, and response and relapse data

\section{Acknowledgments}

The large data source of DGCD relies on the entry of relevant data by the clinicians. We thank all of our colleagues from Denmark's gynecological, pathology, and oncological wards for their thorough work. Data in the DGCD are collected in accordance with current Danish data protection laws. The Data Protection Agency and the National Board of Health govern the laws and procedures for data access to DGCD. This paper was funded by the Program for Clinical Research Infrastructure (PROCRIN) established by the Lundbeck Foundation and the Novo Nordisk Foundation and administered by the Danish Regions.

\section{Disclosure}

The authors report no conflicts of interest in this work.

\section{References}

1. DGCG Executive Committee. DGCD Regulations, October 2, 2013. $\S 6.2$.

2. The Danish Ministry of Health and prevention, Declaration of Approval of Clinical Quality Databases. Declaration nr 459 of 16/05/2006 §1, part 4. Availiable from: http://www.retsinformation. dk. Accessed November 11, 2015

3. Danish Gynecological Cancer Database. National report 2014/2015. Available from: http://www.dgcg.dk/images/rsrapport_DGCD_201415.pdf. Accessed February 6, 2016.

4. Danish Gynecological Cancer Database. National report, 2011. Available from: http://www.dgcg.dk/images/DGCD rsrapport 2011.pdf. Accessed February 6, 2016

5. Advanced quality management system [database on the Internet] Advanced quality database. Available from: http://www.advancedquality. com/qms-database-pages/. Accessed November 11, 2015.

6. Danish Gynecological Cancer Group [homepage on the Internet]. Available from: http://www.dgcg.dk. Accessed February 6, 2016.

7. Fagö-Olsen CL, Hogdall C, Kehlet H, Christensen IJ, Ottesen B. Centralized treatment of advanced stages of ovarian cancer improves survival: a nationwide Danish survey. Acta Obstet Gynecol Scand. 2011;90(3):273-279.

8. Håkansson F, Hogdall EV, Nedergaard L, et al. Risk of malignancy index used as a diagnostic tool in a tertiary centre for patients with a pelvic mass. Acta Obstet Gynecol Scand. 2012;91(4):496-502.

9. Svolgaard O, Lidegaard O, Nielsen ML, et al. Lymphadenectomy in surgical stage I epithelial ovarian cancer. Acta Obstet Gynecol Scand. 2014;93(3):256-260.

10. Juhl CS, Hansen ES, Hogdall CK, Ortoft G. Valid and complete data on endometrial cancer in the Danish Gynaecological Cancer Database. Dan Med J. 2014;61(6):A4864.

11. Petri AL, Kjaer SK, Christensen IJ, et al. Validation of epithelial ovarian cancer and fallopian tube cancer and ovarian borderline tumor data in the Danish Gynecological Cancer Database. Acta Obstet Gynecol Scand. 2009;88(5):536-542.

12. Sperling C, Noer MC, Christensen IJ, Nielsen ML, Lidegaard O, Hogdall C. Comorbidity is an independent prognostic factor for the survival of ovarian cancer: a Danish register-based cohort study from a clinical database. Gynecol Oncol. 2013;129(1):97-102.

13. Bojesen SE, Pooley KA, Johnatty SE, et al. Multiple independent variants at the TERT locus are associated with telomere length and risks of breast and ovarian cancer. Nat Genet. 2013;45(4):371-384, 384e1-2.

14. Karlsen MA, Sandhu N, Hogdall C, et al. Evaluation of HE4, CA125, risk of ovarian malignancy algorithm (ROMA) and risk of malignancy index (RMI) as diagnostic tools of epithelial ovarian cancer in patients with a pelvic mass. Gynecol Oncol. 2012;127(2):379-383.

15. Hogdall C, Fung ET, Christensen IJ, et al. A novel proteomic biomarker panel as a diagnostic tool for patients with ovarian cancer. Gynecol Oncol. 2011;123(2):308-313.

16. Danish Cancer Biobank [homepage on the Internet]. Available from: http://www.cancerbiobank.dk/. Accessed February 6, 2016.

17. Petri AL, Simonsen AH, Hogdall E, et al. Comparison of proteomic biomarker panels in urine and serum for ovarian cancer diagnosis Proteomics Clin Appl. 2010;4(3):304-314.

18. dmcg.dk [homepage on the Internet]. DMCG.dk Benchmarking Consortium. Available from: http://dmcg.dk/dmcgdk-benchmarkingconsortium/. Accessed February 6, 2016.

19. Edwards HM, Noer MC, Sperling CD, et al. Survival of Ovarian Cancer Patients in Denmark: Results from the Danish Gynaecological Cancer Group (DGCG) Database, 1995-2012. Acta Oncologica. In press 2016. 


\section{Publish your work in this journal}

Clinical Epidemiology is an international, peer-reviewed, open access, online journal focusing on disease and drug epidemiology, identification of risk factors and screening procedures to develop optimal preventative initiatives and programs. Specific topics include: diagnosis, prognosis, treatment, screening, prevention, risk factor modification,

Submit your manuscript here: http://www.dovepress.com/clinical-epidemiology-journal systematic reviews, risk \& safety of medical interventions, epidemiology \& biostatistical methods, and evaluation of guidelines, translational medicine, health policies \& economic evaluations. The manuscript management system is completely online and includes a very quick and fair peer-review system, which is all easy to use. 